\title{
ГИДРОФИЗИЧЕСКИЕ ПРОЦЕССЫ
}

\section{СЕЙШИ ПЕТРОЗАВОДСКОЙ ГУБЫ ОНЕЖСКОГО ОЗЕРА 1}

\author{
(C) 2019 г. В. А. Иванов ${ }^{1}$, Н. И. Пальшин ${ }^{2}$, Ю. В. Манилюк ${ }^{1, *}$ \\ ${ }^{\prime}$ ФИЦ “Морской гидрофизический институт РАН” \\ Россия 299011 Севастополь \\ ${ }^{2}$ КарНЦ РАН, Институт водных проблем Севера \\ Россия 185030 Петрозаводск \\ *e-mail: uvmsev@yandex.ru \\ Поступила в редакцию 14.01.2018 г. \\ После доработки 26.03.2018 г. \\ Принята к публикации 11.04.2019 г.
}

\begin{abstract}
Проведен анализ данных натурных наблюдений за колебаниями уровня и скоростями течений в Петрозаводской губе Онежского озера, выполненных в 2016-2017 гг. Измерения колебаний уровня проводились с дискретностью 10 с при помощи двух приборов “TDR-2050” (“RBR Ltd.”, Kaнада). Спектральный анализ выполнялся методом простого преобразования Фурье после одноминутного усреднения данных с целью уменьшения приборных шумов. Выделены энергонесущие периоды, соответствующие модам сейш Петрозаводской губы и Онежского озера. Скорости течений измерялись приборами “Aquadopp HR-Profiler” (“Nortek”, Норвегия). В рамках линейного приближения теории длинных волн рассмотрены сейшевые колебания в модельном бассейне, аппроксимирующем Петрозаводскую губу с учетом Ивановских о-вов. С помощью аналитического решения получены оценки периодов старших мод сейш и соответствующих им максимальных скоростей волновых течений для Петрозаводской губы. Проведено сопоставление теоретических оценок с данными натурных наблюдений, показавшее удовлетворительное соответствие.
\end{abstract}

Ключевые слова: сейши в заливе, свободные волны, длинные волны, волновые течения, бассейн с открытым входом, аналитические решения, мода Гельмгольца, Петрозаводская губа, Онежское озеро.

DOI: $10.31857 / \mathrm{S} 0321-0596465503-510$

\section{ВВЕДЕНИЕ}

Сейши в ограниченных бассейнах - одно из наиболее часто наблюдаемых явлений. Они вносят значительный вклад в формирование их гидрологических режимов, так как охватывают весь объем жидкости в водоеме. Сейши в бухте могут быть причиной такого явления, как тягун [2]. При этом колебания уровня невелики, но могут иметь место значительные периодические возвратно-поступательные движения воды, приводящие к ударам судов о причалы или друг о друга, обрыву швартовых, затруднению или полному прекращению погрузо-разгрузочных операций. Также в проливах сейши вызывают сильные течения, затрудняющие судоходство [2].
Петрозаводская губа находится в западной части Онежского озера и вытянута на 14 км с северо-запада на юго-восток (рис. 1). Ширина губы составляет 6 км, средняя глубина $15 \mathrm{M}$. Петрозаводская губа играет важную роль в жизни Республики Карелии. На ее берегу расположен г. Петрозаводск, в черте которого находятся пассажирский и торговый порты, экранопланостроительное объединение “Орион”, судостроительно-судоремонтный завод и другие хозяйственные предприятия. Она используется для рыбного промысла и любительского рыболовства, служит источником питьевого, коммунально-бытового и промышленного водоснабжения, а также приемником сточных вод города.

\footnotetext{
${ }^{1}$ Работа выполнена в Морском гидрофизическом институте РАН в рамках государственного задания (тема 0827-2018-0004 “Комплексные междисциплинарные исследования океанологических процессов, определяющих функционирование и эволюцию экосистем прибрежных зон Черного и Азовского морей”, шифр “Прибрежные исследования”); в ФИЦ КарНЦ РАН, Институте водных проблем Севера в рамках государственного задания (тема 0223-2015-0005 “Роль гидрофизических процессов в экосистемах мелководных озер. Процессы переноса и перемешивания в годовом цикле”).
} 


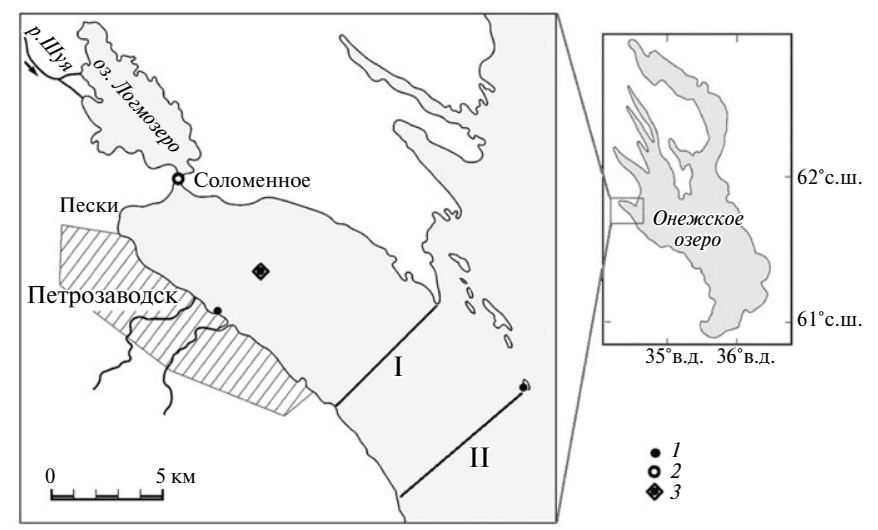

Рис. 1. Картосхема Петрозаводской губы и места измерений сейшевых колебаний: 1 - самописцами уровня “Валдай” в 1964-1968 гг., 2 - самописцем течений RCM в феврале 1987 г., 3 - комплексные исследования в марте 2016 и 2017 гг. I и II границы губы и Петрозаводского Онего. Область, выделенная прямоугольником в правой части рисунка, соответствует левой части рисунка.

Гидрологический режим Петрозаводской губы изучен еще недостаточно. Историю данного вопроса можно найти в [3]. Современные исследования сейшевых колебаний в ней и в Онежском озере в целом были начаты в 1960-х гг. Петрозаводской обсерваторией СЗУГМС и Лабораторией озероведения в 1964-1968 гг. проведены длительные наблюдения за уровнем воды в периоды, когда озеро свободно ото льда. Измерения в Петрозаводской губе осуществлялись самописцами уровня “Валдай”, устанавливаемыми у пассажирской пристани и у о. Ивановский. Затем исследования возобновились в 1987 г. В Соломенском проливе между Петрозаводской губой и о. Логмозеро 9-16 февраля 1987 г. измерялись параметры течений с помощью размещенного подо льдом автономного самописца течений RCM норвежской фирмы Aanderaa Instruments. Достаточно широкомасштабные измерения колебаний уровня в Петрозаводской губе были выполнены в 2016 и 2017 гг.

Практический интерес представляет исследование сейшевых колебаний с использованием аналитических методов, позволяющих получить точные решения для бассейнов с простой геометрией. Аналитические решения могут быть использованы при планировании натурных наблюдений, для оценки значений скоростей сейшевых течений, а также для тестирования численных моделей.

Цель настоящей работы - получение оценок параметров сейшевых колебаний в Петрозаводской губе на основе данных натурных наблюдений и аналитических методов.

\section{СЕЙШИ ПО ДАННЫМ НАБЛЮДЕНИЙ 1964-1968 и 1987 гг.}

В результате наблюдений за уровнем Онежского озера в Петрозаводской губе с помощью самописцев “Валдай” у пассажирской пристани и о. Ивановский, выполненных в 19641968 гг., установлено следующее [3]. В районе Ивановских о-вов практически постоянно имели место колебания уровня со средними периодами 4 ч 18 мин (одноузловая продольная сейша Онежского озера) и 2 ч 15 мин (одноузловая поперечная или близкая к ней по периоду двухузловая продольная сейша Онежского озера), амплитуды которых редко превышали 7 см и составляли в среднем 2-3 см. На лимниграммах у пассажирской пристани наиболее энергонесущие периоды составляли 2 ч, 1 ч 50 мин, 1 ч 40 мин и 1 ч 30 мин, максимальные их амплитуды достигали 7-11 см. Реже наблюдались сейши с периодами 1 ч 18 мин - 1 ч 22 мин, а также более высокочастотные моды с периодами 5-7 мин. Обработка данных наблюдений за течениями, выполненных 9-16 февраля 1987 г. [3] в Соломенском проливе между Петрозаводской губой и о. Логмозеро, показала следующее. Отмечаются значительные флуктуации скорости течения от 0 до $37 \mathrm{~cm} / \mathrm{c}$. За период наблюдений отмечено 18 случаев поворота направления стокового течения на противоположное, максимальные скорости которых достигали 4-8 cм/с. Спектральный анализ данных позволил выявить следующие периоды колебаний: 12 ч 24 мин полусуточный лунный прилив; 4 ч 22 мин одноузловая продольная сейша Онежского озера; 2 ч 18 мин - двухузловая продольная и одноузловая поперечная сейша Онежского озера; 1 ч 52 мин, 1 ч 38 мин, 1 ч 20 мин - основные сейшевые колебания Петрозаводской губы; а также 60 мин и другие $n$-е моды высокочастотных сейш. Отметим, что колебания с периодом $\sim 1$ ч часто наблюдались в заливах и открытых частях Онежского озера [3].

\section{МАТЕРИАЛЫ И МЕТОДЫ ИССЛЕДОВАНИЙ}

Исследования в Петрозаводской губе 9-23 марта 2016 г. и 10-21 марта 2017 г. выполнялись в рамках международного междисциплинарного проекта “Ладожское озеро: жизнь подо льдом - взаимодействие процессов подо льдом в результате глобальных изменений”, поддержанного фондом ЭЛЕМО (Швейцария). Измерения колебаний уровня в районе ст. 3 
(рис. 1) проводились при помощи двух приборов “TDR-2050” (“RBR Ltd.”, Канада) с диапазоном давления до 50 дБ, точностью $\pm 0.05 \%$, разрешением $<0.001 \%$ (0.5 мм водного столба). Дискретность измерений 10 с. Один из приборов устанавливался на дно и регистрировал колебания атмосферного давления вместе с колебаниями столба воды над ним. Другой прибор был установлен на горизонте 1.5 м. Он не учитывал вертикальные колебания уровня воды, так как был зафиксирован относительно поверхности льда и колебался вместе с ним. Разница между показаниями приборов позволила рассчитать вертикальные колебания уровня поверхности губы в точке измерений. Скорости течений измерялись приборами "Aquadopp HR-Profiler" ("Nortek", Норвегия), точность - $1 \%$ от измеряемой величины $\pm 0.5 \mathrm{~cm} / \mathrm{c}$. Спектральный анализ выполнялся методом простого преобразования Фурье после одноминутного усреднения данных с целью уменьшения приборных шумов. Спектральные оценки проводились при разных числах степеней свободы. Доверительные интервалы в низкочастотной области с вероятностью 0.95 и 0.05 составляли 0.73 и 1.28 от значений установленных пиков. В высокочастотной области колебаний (с периодами $<32$ мин) доверительные пределы были шире и составляли соответственно 0.43 и 1.75. При разделении колебаний на разные частоты применялись узкополосные цифровые фильтры и скользящие средние, в которых учитывались установленные в результате спектрального анализа периоды колебаний.

В статье [4] получено следующее решение задачи о сейшах в бухте с открытым входом, прямоугольной формы и постоянной глубины, позволяющее рассчитать периоды сейш, отклонения свободной поверхности и составляющие скорости сейшевых течений:

$$
\begin{aligned}
& \tau_{\mathrm{km}}=\frac{4}{\sqrt{\mathrm{g} h}} \frac{a b}{\sqrt{(1+2 \mathrm{k})^{2} b^{2}+4 m^{2} a^{2}}}, \\
& \zeta_{\mathrm{km}}(x, y, t)=\zeta_{0 \mathrm{~km}} \cos \frac{(1+2 k) \pi x}{2 a} \cos \frac{m \pi y}{b} \cos \sigma_{\mathrm{km}} t \\
& u_{\mathrm{km}}(x, y, t)=\zeta_{0 \mathrm{~km}} \sqrt{\frac{\mathrm{g}}{h}} \frac{(1+2 k) b}{\sqrt{(1+2 k)^{2} b^{2}+4 m^{2} a^{2}}} \times \\
& \times \frac{(1+2 k) \pi x}{2 a} \cos \frac{m \pi y}{b} \sin \sigma_{\mathrm{km}} t
\end{aligned}
$$

$$
\begin{aligned}
& v_{\mathrm{km}}(x, y, t)=\zeta_{0 \mathrm{~km}} \sqrt{\frac{\mathrm{g}}{h}} \frac{2 m a}{\sqrt{(1+2 k)^{2} b^{2}+4 m^{2} a^{2}}} \times \\
& \times \frac{(1+2 k) \pi x}{2 a} \sin \frac{m \pi y}{b} \sin \sigma_{\mathrm{km}} t .
\end{aligned}
$$

Здесь использованы следующие обозначения: $x, y$ - декартовы координаты; $\tau, \sigma-$ периоды и частоты мод сейшевых колебаний; $u, v-$ проекции вектора скорости движения жидкости на оси $x, y$ соответственно; $\zeta-$ отклонение свободной поверхности; $\zeta_{0}-$ задаваемое значение амплитуды начального отклонения свободной поверхности жидкости; $h$ - средняя глубина залива; $t$ - время; $\mathrm{g}$ - ускорение свободного падения; $a$ - длина залива $(0 \leqslant x \leqslant a) ; b-$ ширина залива $(0 \leqslant y \leqslant b)$, входу в залив соответствует $x=$ $a, k=0,1,2, \ldots ; m=0,1,2, \ldots$.

Движение жидкости описывалось линейной системой уравнений длинных волн. На твердых боковых границах бассейна ставились условия непротекания, а на жидкой границе - условие равенства нулю отклонения свободной поверхности, означающее, что у входа в бухту расположены узловые линии для всех собственных мод колебаний жидкости в бухте. Предполагалось, что жидкость однородная и несжимаемая, вращение Земли не учитывалось.

\section{РЕЗУЛЬТАТЫ И ОБСУЖДЕНИЕ}

Наблюдения за уровнем в 2016 и 2017 гг. проводились в марте месяце, когда поверхность озера была покрыта льдом. В работе [7] установлено, что ледяной покров практически не влияет на собственные частоты сейшевых колебаний низших мод. Также несущественно влияние силы Кориолиса. Собственные функции при наличии ледяного покрова также очень близки к собственным функциям задачи со свободной поверхностью. Значительное отличие имеет место только при условии жесткого сцепления в окрестности $\sim 100$ м вблизи берега. Теоретические оценки, полученные в [1], показывают, что влияние льда на периоды сейш неоднозначное: в случае неприкрепленного к берегам ледового покрова он увеличивает период колебаний по сравнению с открытой водой, а в случае припайного льда период уменьшается. По инструментальным измерениям в разные сезоны года в Петрозаводской губе Онежского озера, эти отличия небольшие и находятся в пределах точности спектральных оценок. 


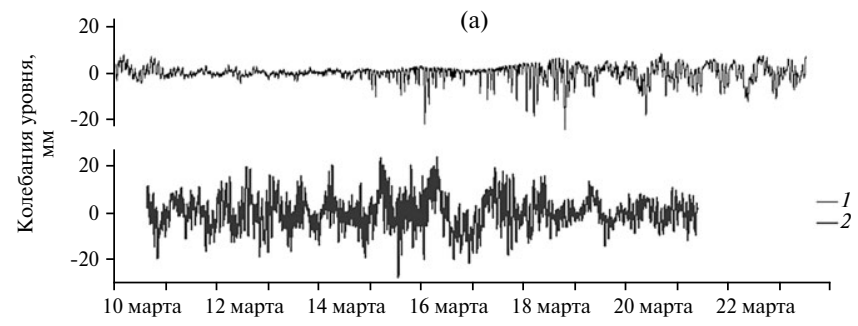

(б)

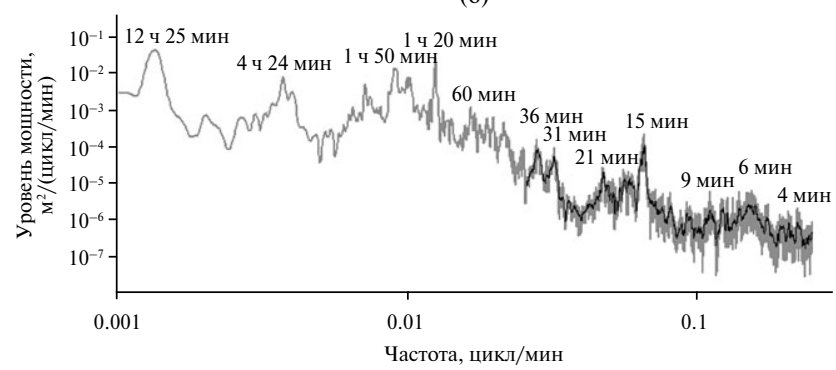

Рис. 2. Колебания уровня на станции измерений в Петрозаводской губе (а): 1 - март 2016 г., 2 март 2017 г.; спектральная плотность мощности колебаний уровня (б).

Спектральный анализ данных наблюдений за колебаниями ледового покрова в марте 2016 и 2017 гг. позволил установить (рис. 2), что в Петрозаводской губе наблюдаются низкочастотные колебания с периодами 12 ч 25 мин, 4 ч 24 мин, 2 ч 19 мин, 1 ч 50 мин, 1 ч 38 мин, 1 ч 20 мин, $\sim 60$ мин. Также выделяются более высокочастотные колебания в интервалах 31-36 мин; 1517 мин ; 8-12 мин и 4-6 мин.

На северо-востоке к Петрозаводской губе примыкают Ивановские о-ва (рис. 1), расстояние между которыми незначительное, и при малых глубинах между ними острова могут аппроксимироваться твердой боковой непроницаемой стенкой, удлиняющей бассейн Петрозаводской губы на 5 км. Эта акватория имеет официальное название - Петрозаводское Онего. Для прямоугольного модельного бассейна с открытым входом и постоянной глубиной, аппроксимирующего Петрозаводскую губу, в котором ось $x$ направлена вдоль губы, а ось $y$ - перпендикулярно ей, рассчитаны периоды мод сейш по формуле (1). Расчет выполнен в двух вариантах (таблица): для Петрозаводской губы без учета Ивановских о-вов ( $a=13 \mathrm{Kм}, b=5 \mathrm{Kм}, h=15$ м) и с учетом Ивановских о-вов ( $a=18 \mathrm{kM}, b=6 \mathrm{KM}, h=16 \mathrm{м}$; острова аппроксимируются твердой непроницаемой стенкой, вплотную примыкающей к побережью губы).

Анализ табл. 1 показывает, что собственные периоды бассейна, аппроксимирующего Петрозаводскую губу, не превышают 2 ч. На основании этого выделим из результатов обработки данных натурных наблюдений глобальные моды бассейна Онежского озера: 12 ч 25 мин, 4 ч 24 мин, 2 ч 19 мин. Колебания с периодом 12 ч 25 мин обусловлены полусуточным лунным приливом. Они наблюдаются и в других крупных озерах [7, 8]. Моды с периодами 4 ч 24 мин и 2 ч 19 мин являются одноузловыми продольной и поперечной сейшами Онежского озера [3]. Колебания с периодами 1 ч 20 мин и 1 ч 38 мин являются модами Гельмгольца Петрозаводской губы и также акватории, прилегающей к ней с учетом Ивановских о-вов (таблица). В наблюдениях присутствует еще один период колебаний - 1 ч 50 мин (рис. 2б), который также был отмечен ранее [3, 5]. Его можно объяснить модой Гельмгольца, если длину акватории Петрозаводское Онего увеличить на $\sim 2$ км до банки на границе с Онежским озером. Периоды и амплитуды остальных мод сейш, связанных с геометрией Петрозаводской губы, значительно меньше. При этом теоретический расчет дает хорошее соответствие с выделенными в результате обработки данных наблюдений интервалов периодов сейш в интервалах 31-36 мин; 15-17 мин; 8-12 мин и 4-6 мин. Исключение составляет период 60 мин, который не получается в результате расчета для бассейна с постоянной глубиной. Данная мода, видимо, связана с неоднородностями батиметрии Петрозаводской губы. В основном все выделенные моды имеют продольную структуру, за исключением мод с периодами 16 и 8 мин, являющимися соответственно одноузловой и двухузловой поперечными сейшами. Таким образом, при моделировании сейш в Петрозаводской губе необходимо учитывать Ивановские о-ва, так как они оказывают существенное влияние на параметры сейшевых колебаний в губе.

Таблица. Периодысейш, рассчитанныедля модельных бассейнов, аппроксимирующих Петрозаводскую губу

\begin{tabular}{c|c|c|c}
\hline \multicolumn{2}{c|}{ Мода } & $\begin{array}{c}\text { Периоды } \tau_{k m}, \text { мин } \\
\text { (без учета }\end{array}$ & $\begin{array}{c}\text { Периоды } \tau_{k m}, \text { мин } \\
\text { (с учетом }\end{array}$ \\
$k$ & $m$ & Ивановских о-вов) & Ивановских о-вов) \\
\hline 0 & 0 & 72 & 96 \\
1 & 0 & 24 & 32 \\
2 & 0 & 14 & 19 \\
3 & 0 & 10 & 13 \\
0 & 1 & 13 & 16 \\
0 & 2 & 7 & 8 \\
1 & 1 & 12 & 14 \\
2 & 1 & 10 & 12 \\
2 & 2 & 6 & 7 \\
\hline
\end{tabular}


(a)

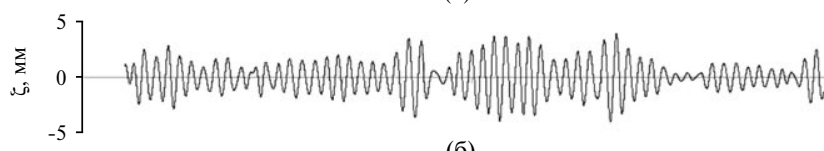

(б)

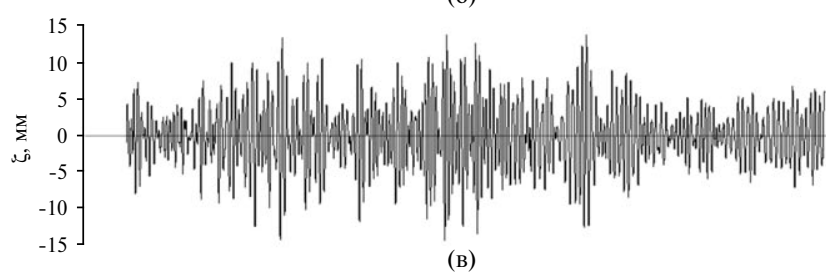

(B)

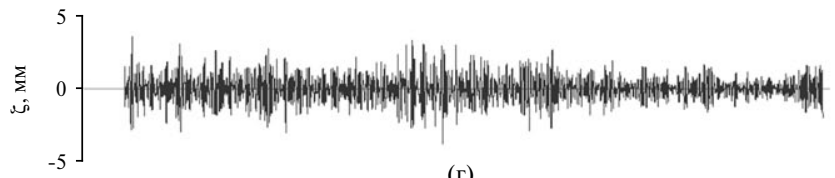

(г)

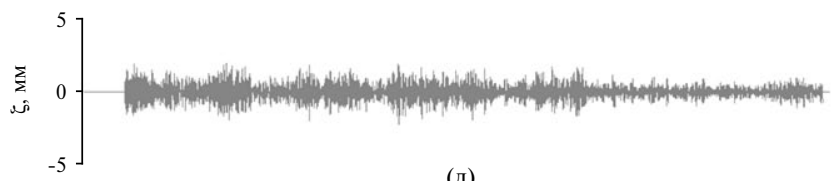

(д)

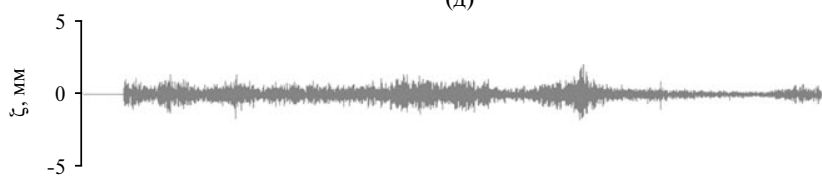

(e)

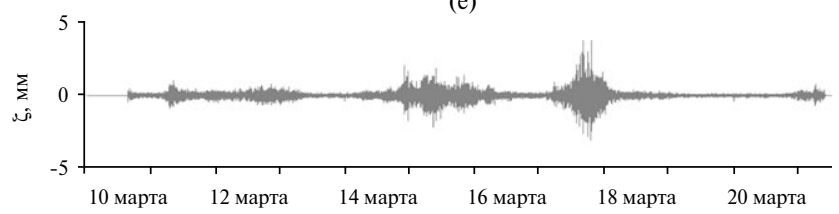

Рис. 3. Отфильтрованные колебания уровня в марте 2017 г. с периодами 4 ч 24 мин (a), 1 ч 20 мин - 1 ч 50 мин (б), 31-36 мин (в), 15-17 мин (г), 8-12 мин (д) и 4-6 мин (е).

Амплитуды вертикальных колебаний уровня воды в марте 2016 и 2017 гг. были небольшими и изменялись от нескольких мм до нескольких см (рис. 2a). Ледовый покров оказывает влияние на максимальные амплитуды колебаний. Зимой они меньше, чем в период открытой водной поверхности [3]. В марте 2017 г. амплитуды колебаний уровня были больше, чем в марте 2016 г., что можно объяснить большим количеством “живых” трещин в ледовом покрове в этот год. Увеличение амплитуд колебаний после 18 марта 2016 г. также можно объяснить образованием трещин в результате усиления скорости ветра до 8-10 м/с в предшествующий период. Сравнение амплитуд колебаний уровня с разными сейшевыми частотами показано на рис. 3. Анализ данного рисунка позволяет сделать вывод, что наибольшие амплитуды (от 5 до 15 мм) имеют низкочастотные колебания. Так, амплитуды одноузловой сейши Онежского озера (4 ч 24 мин) не превышают 5 мм, мод Гельмгольца (1 ч 20 мин, 1ч 50 мин) - 15 мм, одноуз- ловой продольной сейши Петрозаводской губы $(\sim 30$ мин $)-5$ мм.

Из-за того, что наблюдения в 2016, 2017 гг. проводились в основном в одной точке акватории губы (рис. 1), то с их помощью не представляется возможным определить пространственные структуры колебаний уровня и сейшевых течений. Аналитические формулы (2)-(4) позволяют построить картины изолиний уровня и векторные поля скоростей течений. Для примера на рис. 4, 5 приведены изолинии уровня, нормированные на $\xi_{\max }$, и соответствующие им векторные поля скоростей течений для одноузловых продольной и поперечной сейш в модельном бассейне, аппроксимирующем Петрозаводскую губу. Анализ рисунков 4 и 5 показывает, что продольные сейши одномерные, а поперечные сейши - двумерные. Узловая линия одноузловой продольной сейши $\tau_{10}=32$ мин (рис. 4a) расположена в окрестности прямой $x=a / 3$. Наи-
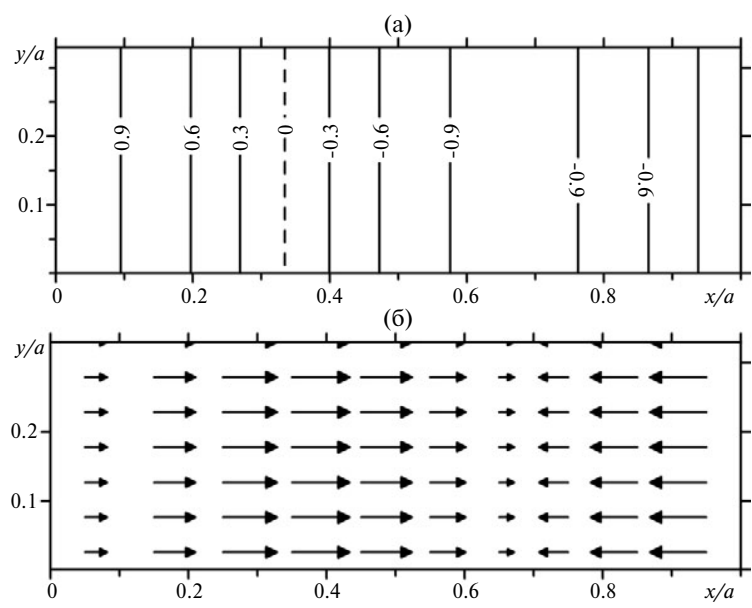

Рис. 4. Изолинии уровня (а), векторное поле скорости течения (б) одноузловой продольной сейши $(k=1, m=0), \tau_{10}=32$ мин.

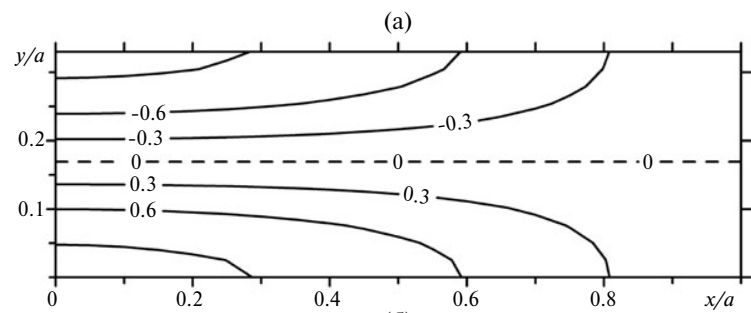

(б)

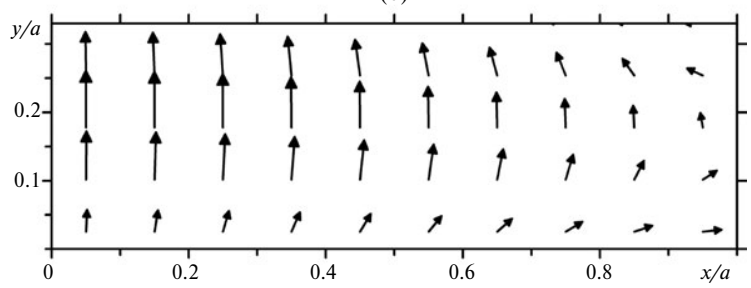

Рис. 5. Изолинии уровня (а), векторное поле скорости течения (б) одноузловой поперечной сейши $(k=0, m=1), \tau_{01}=16$ мин. 
большие отклонения уровня воды от уровня при невозмушенном состоянии происходят в окрестности прямых $x=0, x=2 a / 3$. Сейшевые течения наиболее интенсивны вблизи узловых линий (рис. 4б), их направление сохраняется постоянным на протяжении полупериода волны, затем изменяется на противоположное. Узловая линия одноузловой поперечной сейши $\tau_{01}=16$ мин (рис. 5a) находится на прямой $y=b / 2$, наибольшие отклонения уровня имеют место на боковых стенках: $y=0 ; y=b$. При этом с приближением ко входу в губу интенсивность колебаний уровня заметно уменьшается. Наибольшие скорости течений имеют место в кутовой половине губы.

Аналитическое решение (1)-(4) также позволяет получить оценки максимальных амплитуд колебаний уровня в бассейне и скоростей сейшевых течений по результатам наблюдений за уровнем озера в одной точке для мод сейшевых колебаний, однозначно идентифицируемых по их периоду. Для Петрозаводской губы это относится к моде Гельмгольца $(k=0, m=0)$, а также к одноузловой продольной $(k=1, m=0)$ и одноузловой поперечной $(k=0, m=1)$ сейшам, периоды которых значительно отличаются от периодов других мод (таблица).

Оценим значения параметров сейш для моды Гельмгольца $(k=0, m=0)$. Из таблицы 1 и рис. 2 находим, что к наблюдаемому периоду длительностью 1 ч 38 мин наиболее близок рассчитанный период 1 ч 36 мин, соответствующий моде Гельмгольца. Из (2) получим формулу для вычисления амплитуды сейши данной моды:

$$
Z_{00}=A_{00} \cos ^{-1}\left(\pi x_{o b} /(2 a)\right),
$$

где $A_{00}-$ амплитуда колебаний уровня в точке с абсциссой $x_{o b}$, установленная в результате наблюдений. Из рис. 3 имеем $A_{00} \sim 15$ мм. Так как для станции, на которой измеряется уровень, $x_{\text {ob }} \sim a / 4$, то по формуле (5) получим $Z_{00} \sim 16.2$ мм. В силу этого и с учетом того, что, по данным наблюдений (рис. 3), $A_{00} \in[5 ; 15]$ мм, имеем оценку максимальных амплитуд колебаний уровня для сейши с периодом 1 ч 36 мин в Петрозаводской губе: $Z_{00} \in[5.4 ; 16.2]$ мм.

Оценим амплитуды скоростей сейшевых течений для моды Гельмгольца. Из формулы (4) получаем, что для данной моды $v_{00}=0$. Для вычисления амплитуды составляющей скорости $u_{00}$ имеем из (3) с учетом $h=16$ м следующее выражение:

$$
U_{00}=Z_{00} \sqrt{\frac{\mathrm{g}}{h}}=0.783 Z_{00}
$$

Используя выражение (6), находим, что максимальные скорости течения для колебаний уровня с амплитудами 5.4-16.2 мм составит 4.2$12.7 \mathrm{MM} / \mathrm{c}$.

Анализ соотношения (3) показывает, что амплитуды проекций на ось $x$ составляющих скорости для всех мод продольных сейш $(k \neq 0$, $m=0)$ в прямоугольном бассейне постоянной глубины с открытым входом не зависят от номера моды, ширины и длины бассейна. Они прямо пропорциональны начальному отклонению уровня, обратно пропорциональны корню квадратному от глубины и вычисляются по формулам, аналогичным (6). При этом составляющая скорости $v_{k 0}$ всегда равна нулю, это следует из (4). Получим оценки максимальных отклонений уровня и скоростей течений для одноузловой поперечной сейши. Используя выражение (2), находим:

$$
Z_{10}=A_{10} \cos ^{-1}\left(3 \pi x_{o b} /(2 a)\right),
$$

где $A_{10}-$ амплитуда колебаний уровня в точке с абсциссой $x_{o b}$, установленная в результате наблюдений.

Из рис. 3 имеем $A_{10} \sim 5$ мм. Учитывая, что $x_{o b} \sim a / 4$, по формуле (7) получим максимальное отклонение уровня $Z_{10} \sim 13.1$ мм. Используя формулу (6), находим максимальную скорость течения $U_{10} \sim 10.3 \mathrm{Mm} / \mathrm{c}$.

Получим оценки скоростей волновых течений для поперечных сейш $(\mathrm{m} \neq 0)$. Особенность поперечных сейш в бассейне с открытым входом - то, что они, в отличие от продольных сейш, двумерны. При этом амплитуды скоростей волновых течений поперечных сейш зависят от длины и ширины бассейна, номера моды. Можно показать, что для данного вида сейш величина модуля скорости волновых течений не превосходит величины $\max \left\{U_{\mathrm{km}}, V_{\mathrm{km}}\right\}$. Получим оценку максимума амплитуды скорости волнового течения для первой моды поперечных сейш $(k=0 ; m=1)$. Из формул (3), (4) имеем выражения для расчета амплитуд составляющих волновых скоростей:

$U_{01}=\zeta_{001} \sqrt{\frac{\mathrm{g}}{h}} \frac{b}{\sqrt{b^{2}+4 a^{2}}} ; V_{01}=\zeta_{001} \sqrt{\frac{\mathrm{g}}{h}} \frac{2 a}{\sqrt{b^{2}+4 a^{2}}}$

Для Петрозаводской губы $a>b$. Поэтому и с учетом (8) приходим к выводу, что максимум амплитуды скорости не превосходит $V_{01}$. Подставляя во вторую формулу (8) значения геометрических параметров Петрозаводской губы, имеем: 


$$
V_{01}=0.986 \zeta_{001} \sqrt{\frac{\mathrm{g}}{h}}=0.77 \zeta_{001}
$$

Пункт наблюдения находился вблизи узловой линии одноузловой поперечной сейши (рис. 1, 5a). Поэтому в данном случае выполнять оценочные расчеты для этой моды по данным о колебаниях уровня нецелесообразно. Такие оценки можно будет провести, когда будут получены данные наблюдений на станции, расположенной ближе к берегу губы. Если предположить, что амплитуда колебаний уровня для одноузловой поперечной сейши сопоставима c амплитудой одноузловой продольной сейши, и предположить, что $\zeta_{001}=10 \mathrm{Mм}$, имеем $V_{01}=8 \mathrm{mM} / \mathrm{c}$.

Таким образом, оценочные максимальные скорости течений для моды Гельмгольца составили $1.3 \mathrm{~cm} / \mathrm{c}$, а для одноузловой продольной сейши $-1 \mathrm{~cm} / \mathrm{c}$.

Наблюдения за течениями в марте 2016 и 2017 гг. проводились в периоды развития свободной конвекции. Помимо длинных баротропных волн, на поле скоростей течений в губе в это время оказывали влияние транзитное течение р. Шуи, крупномасштабная геострофическая циркуляция из-за неоднородного распределения плотности воды, а также мезои мелкомасштабные формы движения воды, индуцируемые как неравномерным проникновением солнечной радиации сквозь неоднородный снежно-ледовый покров, так и формированием конвективных ячеек при дневном прогреве. В дневные часы амплитуды колебаний скоростей течений возрастали до $1-2$, а ночью снижались до $0.5-1 \mathrm{~cm} / \mathrm{c}$. Из-за уменьшения доли высокочастотных флуктуаций в ночные часы движения воды имели более правильную периодичность с частотами, близкими к низшим модам сейш (Гельмгольца и первая мода). Амплитуды колебаний высших мод сейш были меньше и составляли $0.1-0.5 \mathrm{~cm} / \mathrm{c}$. Полученные результаты хорошо согласуются с теоретическими расчетами.

\section{ВЫВОДЫ}

На основе обработки данных наблюдений за уровнем Онежского озера и теоретических расчетов в Петрозаводской губе выделены следующие моды сейшевых колебаний:

моды сейш Онежского озера: 12 ч 25 мин (вызывается полусуточным лунным приливом),
4 ч 24 мин, 2 ч 19 мин (вызываются метеопричинами);

моды, определяемые геометрией берегов и глубиной Петрозаводской губы: 1ч 50 мин, 1 ч 38 мин, 1 ч 20 мин, 60 мин; а также более высокочастотные колебания в интервалах 31-36 мин, 15-17 мин, 8-12 мин и 4-6 мин.

Оценочные максимальные отклонения уровня для моды Гельмгольца составляют 16.2 мм, для одноузловой продольной сейши 13.1 мм. При этом амплитуды соответствующих сейшевых течений равны 12.7 мм/с, 10.3 мм/с.

\section{СПИСОК ЛИТЕРАТУРЫ}

1. Зырянов В.Н. Сейши подо льдом // Вод. ресурсы. 2011. Т. 38 . № 3. С. 259-271. DOI: 10.7868/ S0321059616040180

2. Лабзовский Н.A. Непериодические колебания уровня моря. Л.: Гидрометеоиздат, 1971. 238 с.

3. Малинина Т.И., Солнцева Н.О. Сейши Онежского озера // Динамика водных масс Онежского озера. Л.: Наука, 1972. С. 40-73.

4. Манилюк Ю.В., Черкесов Л.В. Исследование сейшевых колебаний в бухте со свободным входом // Мор. гидрофиз. журн. 2017. № 4. С. 16-25. DOI: 10.22449/0233-7584-2017-4-16-25

5. Пальщин Н.И. Термические и гидродинамические процессы в озерах в период ледостава. Петрозаводск: Кар НЦ РАН ИВПС, 1999. 85 с.

6. Смирнов С.В., Кучер К.М., Гранин Н.Г., Стурова И.В. Сейшевые колебания Байкала // Изв. РАН. Физика атмосферы и океана. 2014. Т. 50. № 1. С. 105-116. DOI: $10.7868 / \mathrm{S} 000235151305012 \mathrm{X}$

7. Стурова И.В. Влияние ледяного покрова на колебания жидкости в замкнутом бассейне // Изв. РАН. Физика атмосферы и океана. 2007. Т. 43. № 1. C. $128-135$.

8. Miller G.S., Sailor J.H. Currents and temperatures in Green Bay, Lake Michigan // Int. Assoc. Great Lakes Res. 1985. V. 11. P. 97-109. 


\title{
SEICHES IN PETROZAVODSK BAY OF THE LAKE ONEGO
}

\author{
(C)2019 V. A. Ivanov ${ }^{1}$, N. I. Pal'shin ${ }^{2}$, Yu. V. Manilyuk ${ }^{1, *}$ \\ ${ }^{I}$ Marine Hydrophysical Institute RAS, \\ Russia, 299009, Sevastopol, \\ ${ }^{2}$ Northern Water Problems Institute, \\ Karelian Research Center RAS, \\ Russia, 185030, Petrozavodsk \\ *e-mail:uvmsev@yandex.ru \\ Received: 14.01.2018 \\ Revised version received: 26.03 .2018 \\ Accepted: 11.04.2019
}

\begin{abstract}
The analysis of observation data on fluctuations in the level and velocity of currents in the Petrozavodsk Bay of Lake Onega, performed in 2016-2017, was carried out. Level oscillations were measured with a discreteness of $10 \mathrm{~s}$ using two TDR-2050 devices (RBR Ltd., Canada). Spectral analysis was performed using the simple Fourier transform method after one-minute data averaging to reduce instrument noise. Energycarrier periods corresponding to the seiches of Petrozavodsk Bay and the Lake Onega are identified. Current velocities were measured with Aquadopp HR-Profiler (Nortek, Norway). Within the framework of the linear long wave theory, seiche oscillations are considered in a model basin approximating the Petrozavodsk Bay with regard to the Ivanovskiye Islands. Using an analytical solution, estimates for the periods of the higher seiche modes and the corresponding maximum wave flow velocities are obtained for the Petrozavodsk Bay. The comparison of theoretical estimates with the data of field observations, was showed satisfactory agreement.
\end{abstract}

Keywords: seiches in a bay, free waves, long waves, wave currents, open-entrance basin, analytical solutions, Helmholtz mode, Petrozavodsk Bay, the Lake Onega.

DOI: $10.31857 / \mathrm{S} 0321-0596465503-510$ 